\title{
SPECTRAL FIELD MEASUREMENTS OF WAVE REFLECTION AT A STEEP SHORE WITH WAVE DAMPING CHAMBERS
}

\author{
JAN-VICTOR BJÖRKQVIST ${ }^{1}$, ILKKA VÄHÄAHO ${ }^{2}$ \& KIMMO KAHMA ${ }^{1}$ \\ ${ }^{1}$ Finnish Meteorological Institute, Helsinki, Finland \\ ${ }^{2}$ City of Helsinki, Real Estate Department, Helsinki, Finland
}

\begin{abstract}
Wave reflection at a steep shore radically affects the proper building height and must therefore be taken into account in coastal planning. The reflection of the waves can be partially mitigated by building e.g. wave damping chambers. While there is a great deal of laboratory data available even for irregular waves, field data verifying the effectiveness of different existing structures are sparse. An extensive wave measurement campaign was conducted in the coastal waters of Helsinki in the Baltic Sea, financed by the city. The region has a characteristic archipelago, which affects the wave properties. The reflection of waves was studied by comparing simultaneous measurements from two devices. A wave buoy was moored ca $800 \mathrm{~m}$ from a steep wall, while the wave height was also measured from the shore using a capacitive wave gauge. The coastal structure is equipped with caisson chambers built to damp the waves. Each of the chambers were perforated with two $0.7 \mathrm{~m}$ wide and $3.2 \mathrm{~m}$ high openings. The inside of the chambers are $5.9 \mathrm{~m}$ deep and $4.6 \mathrm{~m}$ wide. By comparing the wave buoy and wave staff spectra we observed that the waves were reflected up to frequencies of about $0.4-0.5 \mathrm{~Hz}$, with the longest waves of about $0.2 \mathrm{~Hz}$ being fully reflected. Waves shorter than $0.45 \mathrm{~Hz}$ (i.e. of order $10 \mathrm{~m}$ ) were not reflected, from which we can draw the conclusion that they were damped by the chambers. The reflection coefficient for the significant wave height was 1.5 for the total significant wave height, 1.7 for waves below $0.45 \mathrm{~Hz}$ and 0.9 for waves above $0.45 \mathrm{~Hz}$. We conclude that a damping chamber of this particular type and dimension is not sufficient for attenuating waves longer than approximately $10 \mathrm{~m}$.

Keywords: wave damping, wave reflection, archipelago, wave run-up, coastal construction.
\end{abstract}

\section{INTRODUCTION}

At a steep shoreline wave reflection radically affects the proper building height. Reflected waves affect the maximum elevation of the so called "green water", i.e. the continuous water mass. In semi-enclosed harbours the reflecting waves might also magnify the wave conditions, which might be problematic for small vessels.

The effect can be mitigated by implementing wave breakers or by building wave damping chambers at the shoreline structures. Caisson wave breakers usually have a fully or partially perforated front wall, first designed by Jarlan [1]. Both single and double chamber partially perforated breakwaters has been tested with experimental laboratory studies [2]. Analytical models has also been developed, even for irregular waves [3]. The effect of oblique incident angles has been touched upon by Lee et al. [4]. The reflection of the waves has in many studies been found to depend on the width of the caisson chamber relative to the incident wave length $[2,3]$.

Because of the cost associated with the building of the structures there are, to our knowledge, no comparative analyses available from the field to quantify the effectiveness of an existing partially perforated caisson chamber. Also, since the determination of the effectiveness of the damping mechanisms require simultaneous wave measurements from two locations to get a representative measurement of both the incident and reflected wave height, they cannot be validated directly as a by-product of single point wave observations near the structures. 

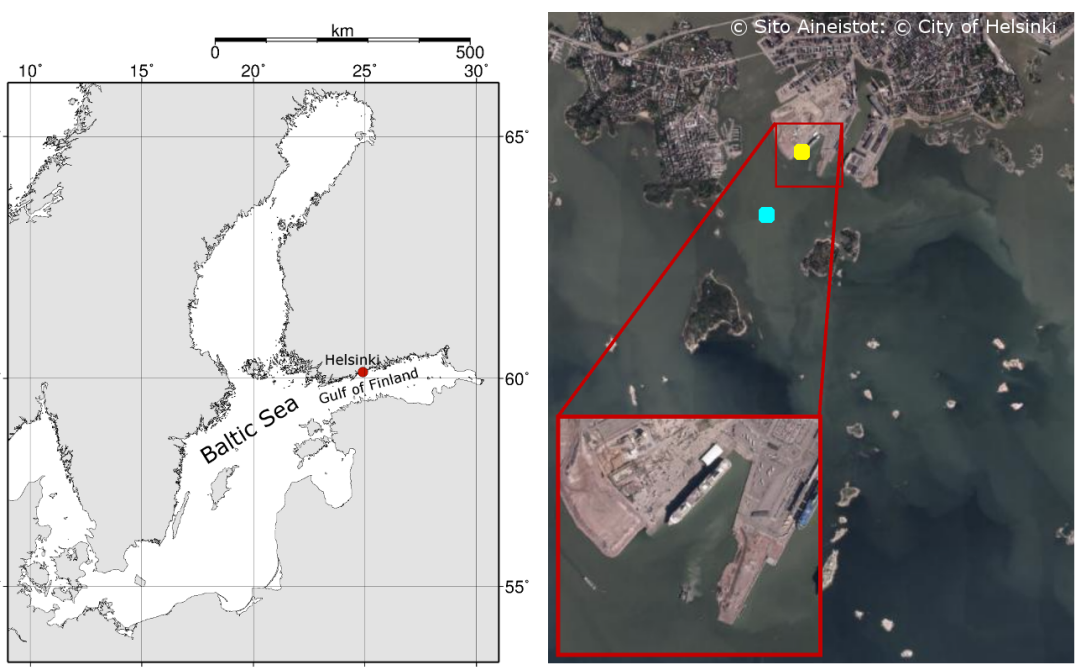

Figure 1: The location of the study area is shown on the left (red dot). The locations of the moored wave buoy (cyan) and the locations of the damping chambers where the wave staff measurements were made (yellow) are shown on the right.

In 2012 the City of Helsinki started an extensive campaign aimed at mapping the wave and wind conditions, as well as the sea level variations along the scattered coastal archipelago [5]. The measurements were performed by the Finnish Meteorological Institute as a part of this commissioned project. The main result was the joint effect of the sea level and wave run-up, which was also visualised on a dedicated website [6]. As a part of this campaign, also the wave reflection was explicitly measured.

In this paper we present a study of the effectiveness of an existing construction that has been built at the coast of Helsinki, Finland. The harbour is equipped with a caisson structure consisting of 22 partially perforated single chambers. We quantified the incident wave field using a moored wave buoy, while the reflected wave field is measured with a capacitive wave gauge from the shore.

\section{EXPERIMENTAL SETUP}

\subsection{Study area and wave damping chambers}

The study area is located at the coast of Helsinki. Helsinki is located in the northern coast of the Gulf of Finland (GoF) in the Baltic Sea (Fig. 1). The study area is sheltered by a coastal archipelago, meaning that the wave field is typically a combination of shorter locally generated wind waves and longer attenuated waves propagating from the GoF. The propagating waves are subjected to wave refraction and diffraction in the archipelago.

The water depth at the measuring places is 10-20 metres, meaning that the longer open sea waves are interacting with the bottom. The wave length is decreased because of the water depth, but there is no depth-induced wave breaking caused by wave-bottom interaction.

The coastal structure is equipped with partially perforated caisson chambers that were built to damp the waves (Figs 2 and 3). The inside of the chambers are $4.6 \mathrm{~m}$ wide and $5.9 \mathrm{~m}$ deep. The free space in the chambers are roughly $4.5 \mathrm{~m}$ high. The chambers are partially 


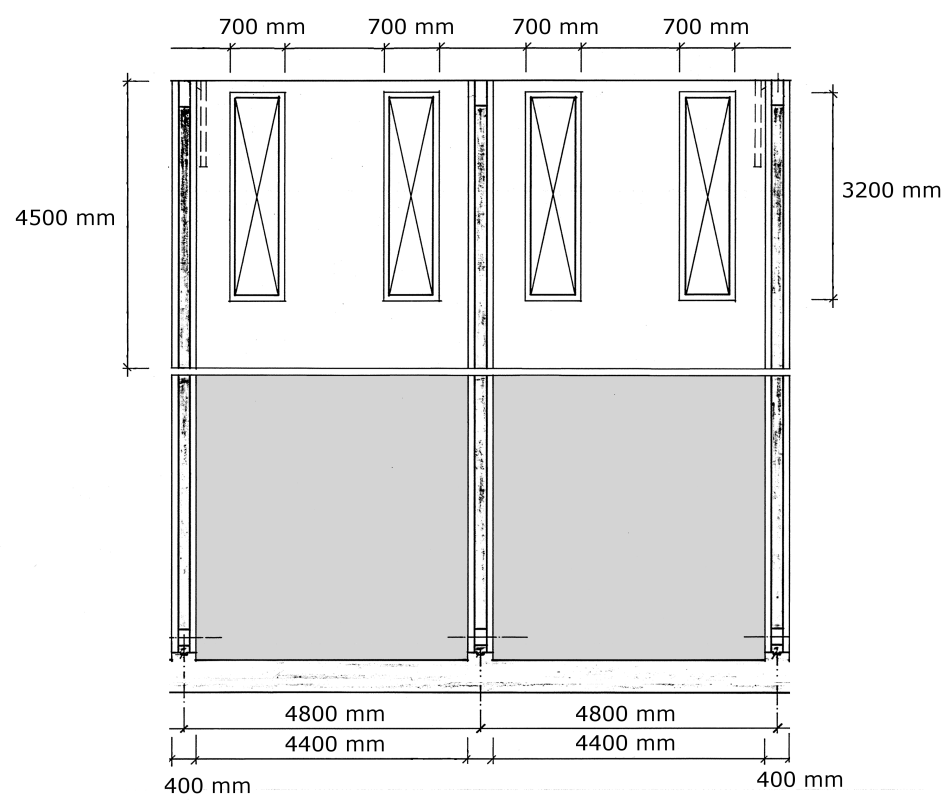

Figure 2: Front view of the partially perforated chambers. The gray area visualises the filling of the chamber.

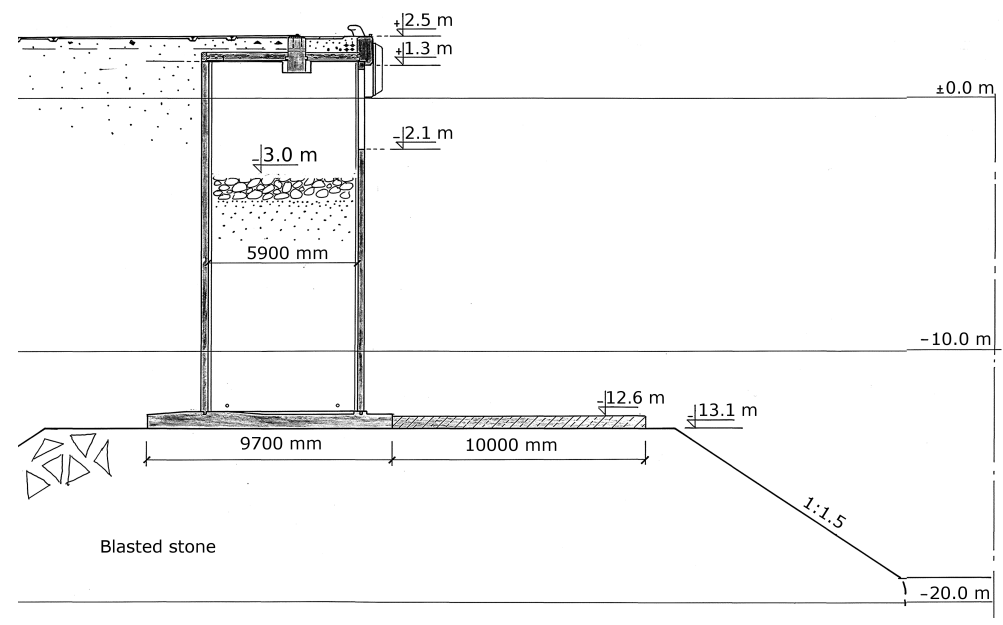

Figure 3: Side view of a caisson chamber where the wave measurements were made. The dimensions and the different heights are shown in shown in millimetres and metres respectively.

perforated with two $0.7 \mathrm{~m}$ wide and $3.2 \mathrm{~m}$ high openings, meaning that the perforations cover almost the entire free space. 


\subsection{Wave measurements}

A GPS-based Datawell model DWR-G4 wave buoy was moored ca $800 \mathrm{~m}$ from a steep wall at $60^{\circ} 08.64^{\prime} \mathrm{N} 24^{\circ} 54.12^{\prime} \mathrm{E}$ (Fig. 1). The directional wave buoy measurements were made between 02 October and 01 November 2012. The sampling frequency of the DWR-G4 is $1.28 \mathrm{~Hz}$.

The wave measurements at the wall was made using a capacitive wave gauge that measures the water lever elevation with a $5 \mathrm{~Hz}$ sampling frequency. A total of four 20 minute time series were recorded with the wave gauge.

We calculated the wave spectra for both the devices from 20 min vertical displacement time series tapered using a Blackman-Harris window and averaging 31 of the resulting frequency bins. Following the method presented by Björkqvist et al. [7], we corrected the wave buoy spectra for low-frequency artefacts caused by a momentary loss of the GPSsignal. The directional wave spectra was estimated from the wave buoy data with the Maximum Likelihood Method [8], which was applied using the code by Drennan et al. [9]. No directional information is available near the wall, since that device only has a single wave gauge.

The significant wave height in this paper is defined as

$$
H_{s}=H_{m_{0}}=4 \sqrt{m_{0}},
$$

where $m_{0}$ is the zeroth moment of the wave spectrum, which is also the variance of the vertical displacement time series. The reflection coefficient is defined as

$$
K=\frac{H_{m_{0, R}}}{H_{m_{0, I}}}=\sqrt{\frac{m_{0, R}}{m_{0, I}}},
$$

where $H_{m_{0, I}}$ and $H_{m_{0, R}}$ are the incident and the reflected significant wave heights respectively. In this study, the wave buoy measurements are taken to represent the incident wave field, while the wave gauge measurements at the shore are taken to represent the reflected wave field.

Both the wave buoy and the wave gauge can only measure the frequency of the waves, not the wavelength. However, the wavelength $L$ of a wave with the frequency $f$ can be estimated from linear wave theory by solving the implicit dispersion relation

$$
c^{2}=\frac{g}{k} \tanh (k h),
$$

where $c=\omega / k$ is the phase speed of the wave, $g$ is the acceleration due to gravity, $\omega=2 \pi f$ is the angular frequency and $k=2 \pi / L$ is the wavenumber.

\section{RESULTS}

We compared the simultaneous measurements from the moored wave buoy and the capacitive wave gauge. The basic wave parameters during the time of coinciding measurements are listed in Table 1. The wave conditions stayed relatively constant during the entire 1.5 hours. The only bigger change was the peak period measured by the wave buoy. In the beginning the local wind system was slightly more dominant than the longer waves propagating from the GoF, but as can be readily seen from the wave spectra in Fig. 4, the actual change was marginal at best. For the wave gauge measurements the longer waves were more dominant throughout the measurements, since they were strongly reflected. 
Table 1: The wave parameters for both the moored wave buoy and the wave gauge for the times the wave gauge was measuring.

\begin{tabular}{cccccc}
\hline & \multicolumn{2}{c}{ Wave buoy } & & \multicolumn{2}{c}{ Wave gauge } \\
\cline { 2 - 3 } \cline { 5 - 6 } Time (UTC) & $H_{s}(\mathrm{~m})$ & $T_{p}(\mathrm{~s})$ & & $H_{s}(\mathrm{~m})$ & $T_{p}(\mathrm{~s})$ \\
\hline $09: 50-10: 10$ & 0.34 & 3.1 & & 0.54 & 5.2 \\
$10: 10-10: 30$ & 0.35 & 2.7 & & 0.58 & 5.2 \\
$10: 30-10: 50$ & 0.37 & 5.2 & & 0.50 & 5.2 \\
$11: 00-11: 20$ & 0.32 & 5.2 & & 0.56 & 5.2 \\
\hline
\end{tabular}
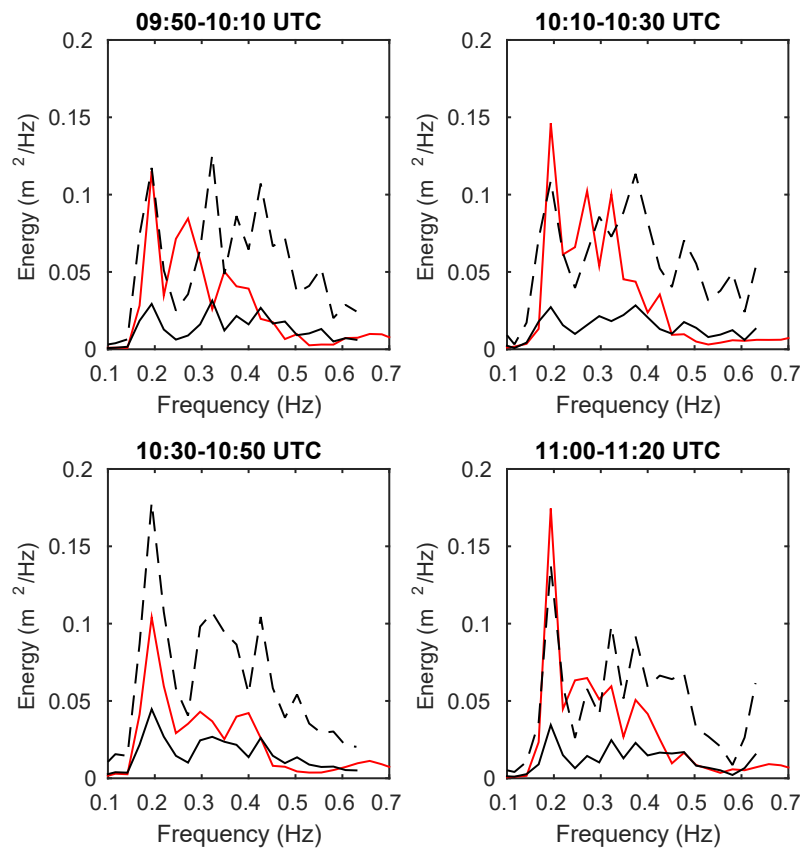

Figure 4: The wave spectrum from the wave gauge (red), the wave buoy (black) and a hypothetical fully reflected wave buoy (dashed black).

The use of the wave buoy measurements as an incident wave field is appropriate, since there are no reflected waves observed in the directional wave spectrum (Fig. 5). The wave growth between the wave buoy and the wave staff cannot be reliably quantified because of a lack of wind measurements. However, based on wind measurement about $6 \mathrm{~km}$ further out from the outer archipelago, the wind speed was under $10 \mathrm{~m} / \mathrm{s}$. Using the growth relations from Kahma and Calkoen [10] we quantified the wave growth to be at most $2-3 \mathrm{~cm}$ in the total significant wave height. This effect can therefore safely be ignored in our calculations.

By comparing the wave buoy and wave staff spectra we observed that the waves were reflected up to frequencies of about $0.4-0.5 \mathrm{~Hz}$, with the longest waves of about $0.2 \mathrm{~Hz}$ being fully reflected (Fig. 4). The narrow wave spectra at $0.2 \mathrm{~Hz}$ (ca $40 \mathrm{~m}$ wavelength) indicate that they are refracted waves, which is to be expected in the coastal archipelago. Waves shorter 


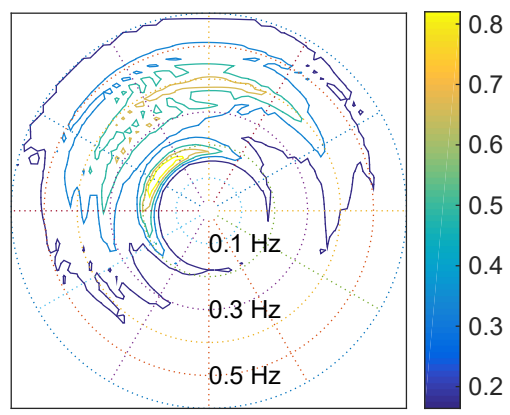

Figure 5: The normalized directional wave spectrum 09:54-10:24 UTC estimated from the wave buoy measurements using the Maximum Likelihood Method. No reflected waves are observed in the incident wave field. The plot shows the propagation direction of the waves.

Table 2: The reflection coefficient for the significant wave height. The wave field measured by the wave buoy represents the incident wave field and the wave gauge measures the reflected wave field at the wave damping chambers.

\begin{tabular}{cccc}
\hline & \multicolumn{3}{c}{$K$ (Refl. coef.) } \\
\cline { 2 - 4 } Time (UTC) & $f<0.45 \mathrm{~Hz}$ & $f \geq 0.45 \mathrm{~Hz}$ & All freq. \\
\hline $09: 50-10: 10$ & 1.72 & 0.82 & 1.48 \\
10:10-10:30 & 1.79 & 0.84 & 1.57 \\
10:30-10:50 & 1.39 & 0.84 & 1.27 \\
$11: 00-11: 20$ & 1.86 & 0.97 & 1.64 \\
$09: 50-11: 20$ & 1.68 & 0.86 & 1.49 \\
\hline
\end{tabular}

than $0.45 \mathrm{~Hz}$ (i.e. of order $10 \mathrm{~m}$ ) were not reflected, from which we can draw the conclusion that they were damped by the chambers.

When calculating the reflection coefficient $K$, we only integrated the wave gauge spectrum to the Nyquist-frequency of the wave buoy, i.e. $0.64 \mathrm{~Hz}$, since otherwise the energy of the higher frequencies would skew the comparison. The reflection coefficients for all the four measured time series are presented in Table 2. We also calculated the reflection coefficient from the wave spectrum that was an average of all four spectra. The reflection coefficient for the significant wave height was 1.5 for the total significant wave height, 1.7 for waves below $0.45 \mathrm{~Hz}$ and 0.9 for waves above $0.45 \mathrm{~Hz}$.

\section{SUMMARY}

We performed a field study of wave reflection at a steep shore in the Gulf of Finland (GoF). The incident wave field was quantified using a wave buoy moored $800 \mathrm{~m}$ from the shore, where the reflected wave field was measured with a wave gauge. The shoreline has a caisson structure and is equipped with partially perforated wave damping chambers.

Our measurements show that the chambers are not sufficient to damp the longer waves (ca $40 \mathrm{~m}$ wavelength) propagating through the coastal archipelago from the GoF. These wavelengths are fully reflected in spite of the wave damping chambers. Shorter waves are not fully reflected and waves with a frequency higher than roughly $0.45 \mathrm{~Hz}$ (order $10 \mathrm{~m}$ 
wavelength) are even damped. The reflection coefficient for the significant wave height based on all the experimental data is 1.5 (1.7 and 0.9 for wave under and over $0.45 \mathrm{~Hz}$ respectively).

These results are not in line with studies showing that the damping of a partially perforated caisson chamber is most effective when the ratio between the depth of the champer $(5.9 \mathrm{~m}$ in this study) and the wavelength is around 0.15-0.25 [2,3]. However, Lee et al. [4] have shown that the incident angle affects the damping ability of perforated structures. Moreover, the rubble mound west of the measurement location at the shore (Fig. 1) can easily reflect waves, thus amplifying the wave height in front of the wave chambers.

We conclude that a damping chamber of this particular type and dimension is not sufficient for attenuating waves longer than approximately $10 \mathrm{~m}$, at least when the incident angle is oblique. Wave shorter than order $10 \mathrm{~m}$ are damped, which might also be because of their less oblique incident angle.

\section{REFERENCES}

[1] Jarlan, G., A perforated vertical wall breakwater. The Dock \& Harbour Authority, XII486, pp. 394-398, 1961.

[2] Lee, J.I. \& Shin, S., Experimental study on the wave reflection of partially perforated wall caissons with single and double chambers. Ocean Eng., pp. 1-10, 2014.

[3] Suh, K.D., Park, J.K. \& Park, W.S., Wave reflection from partially perforated-wall caisson breakwater. Ocean Eng., 33, pp. 264-280, 2006.

[4] Lee, J.I., Kim, Y.T. \& Shin, S., Experimental studies on wave interactions of partially perforated wall under obliquely incident waves. The Scientific World Journal, 2014.

[5] Kahma, K.K., Björkqvist, J.-V., Johansson, M., Jokinen, H., Leijala, U., Särkkä, J., Tikka, K. \& Tuomi, L., Turvalliset rakentamiskorkeudet Helsingin rannoilla 2020, 2050 ja 2100, 2016. In Finnish with English abstract.

[6] City of Helsinki, http://www.hel.fi/static/kv/Geo/Vesi/PoijutEn.html, Accessed on: 21.11.2016.

[7] Björkqvist, J.-V., Pettersson, H., Laakso, L., Kahma, K.K., Jokinen, H. \& Kosloff, P., Removing low-frequency artefacts from Datawell DWR-G4 wave buoy measurements. Geosci. Instrum. Method Data Syst., 5, pp. 1-9, 2016.

[8] Capon, J., High-resolution frequency-wavenumber spectrum analysis. Proc. IEEE, 57, pp. 1408-1418, 1969.

[9] Drennan, W., Donelan, M.A., Madsen, N., Katsaros, K.B., Terray, E.A. \& Flagg, C.N., Directional wave spectra from a swath ship at sea. Journal of Atmospheric and Oceanic Technology, 11, pp. 1109-1116, 1994.

[10] Kahma, K.K. \& Calkoen, C., Reconciling discrepancies in the observed growth of windgenerated waves. J. Phys. Oceanogr., 22, pp. 1389-1405, 1992. 